\title{
Socio-demographic risk factors for unintended pregnancy among unmarried adolescent Nigerian girls
}

\author{
Chibuogwu Izugbara ${ }^{a, b *}$ \\ ${ }^{a}$ Human Economy Programme, University of Pretoria, Pretoria, South Africa \\ ${ }^{b}$ Department of Sociology, University of Pretoria, Pretoria, South Africa \\ *Corresponding author, email: cizugbara@yahoo.com
}

Background: Globally, unintended births among unmarried adolescent girls are a major contributor to maternal and childhood mortality, the vicious cycle of ill-health, poverty, and truncated educational opportunities. Nigeria has the highest rates of adolescent fertility in sub-Saharan Africa. Over 900000 births to adolescents occur annually and 150 out of every 1000 women who give birth in Nigeria are 19 years old or under.

Objective: To document and investigate socio-demographic risk factors for unintended pregnancy among unmarried adolescent Nigerian girls.

Methods: Data for this study were drawn from the 2008 Nigeria Demographic and Health Survey. Univariate and multivariate statistical analyses were used to assess the relationship between adolescent pregnancy and socio-demographic contextual factors focusing on sex and age of household head, adolescent girls' age, and educational attainment, place of residence, religious affiliation, and household wealth index. All data were analysed using STATA Version 11.

Results: Non-pregnant adolescents had older household heads; such households were wealthy, and parents of such households had higher educational standing. Female-headed households were less likely to experience unwanted adolescent pregnancy compared to those of the reference group category $(\mathrm{OR}=0.56,95 \% \mathrm{Cl}=0.3920-0.8073)$.

Conclusion: There is a significant relationship between age and sex of household head and risk of unintended adolescent pregnancy among unmarried adolescent girls. Adolescent girls from households headed by young adults are more likely to experience adolescent pregnancy compared to adolescent girls from households headed by older adults.

Keywords: adolescent pregnancy, age and household headship, Nigeria, sex

\section{Introduction}

Unintended births among unmarried adolescent girls are a major contributor to maternal and childhood mortality, the vicious cycle of ill-health, poverty, and truncated educational opportunities. ${ }^{1}$ For example, it affects both physiological and psychosocial aspects of the adolescent. ${ }^{2}$ Pregnant adolescents have greater risks than adults for sexually transmitted infections (STDs), especially HIV-1 infection. ${ }^{3}$ They also experience more anaemia, severe preeclampsia/eclampsia, placental abruption, intrauterine foetal death, and caesarean delivery. ${ }^{4}$ Not only does adolescent pregnancy have maternal implications, it also affects infants. Low birth weight (LBW) infants, premature delivery, and foetal distress have been found to be greater among adolescent than in adult pregnancies. ${ }^{5}$ Recent estimates by UNICEF ${ }^{6}$ indicate that $14 \%$ of all unsafe abortions in developing societies are among adolescent mothers. More so, stillbirths and death in the first week of life are 50\% higher among babies born to adolescent mothers than among babies born to older mothers. ${ }^{7}$ Globally, the rates of population growth are more rapid when women have their first child in their teen years, because early initiation into childbearing lengthens the reproductive period and subsequently increases fertility. ${ }^{8}$

Research shows that sub-Saharan Africa has the world's highest level of adolescent childbearing - 143 births per 1000 girls aged 15-19 years. ${ }^{6}$ However, in sub-Saharan Africa, Nigeria has the highest rate of adolescent fertility. According to ${ }^{1}$ estimates, over 900000 births to adolescents occur annually and 150 out of every 1000 women who give birth in Nigeria are 19 years old or under. A review of literature on the causes of unintended birth among adolescents in Nigeria found a modest number of studies. ${ }^{9,10}$ Studies found strong associations between early onset of menarche among females, ${ }^{11}$ early initiation of sexual activity, economic insecurity, low and ineffective use of contraception, and deterioration in the traditional African values. ${ }^{12,13}$ Other studies have focused on self-care and health-promoting behaviours. Among those, several studies asked whether certain factors such as self-efficacy, self-esteem, social support, and intention to have a baby, level of education, occupation, income, and health perception influenced healthy behaviour patterns in pregnant adolescents. ${ }^{14,15}$ Other studies have identified the influence of a number of individual and family factors on adolescent sexual behaviour such as individual psychosocial factors of age at first intercourse, self-esteem, and gender of adolescents. ${ }^{16,17}$ Adolescents are also influenced by their peers and family members. ${ }^{18}$

Researchers have also studied how parent/child connectedness might lower adolescent pregnancy risk. ${ }^{19,20}$ In such studies, close mother/daughter relationships were found to be related to daughters' postponement of sexual intercourse. ${ }^{21}$ Some other studies which examined the interaction between religion and social attitudes and behaviour of adolescents, including their sexual views and practices ${ }^{22,23}$ observed that highly religious teens (e.g. those with high levels of religious commitment, religious attendance, religious salience, and prayer) initiate sexual activity later and report fewer sexual partners than do their less religious peers. Other studies discussed the influences of adolescent sexuality ${ }^{22}$ and adolescent perception of sexuality and sexually transmitted infections. ${ }^{24}$ The ethnography of gender, economics, and the power dynamics of sexuality in southwestern Nigeria has also been studied. ${ }^{16}$ 
It appears reasonable to conclude that, although some evidence does exist, the issue of unintended births among Nigerian adolescents and its underlying determinants remain inadequately understood. Studies have shown that delaying adolescent births could significantly lower population growth rates, potentially generating broad economic and social benefits, in addition to improving the health of adolescents. ${ }^{18}$

The purpose of this study is to document and investigate socio-demographic risk factors for unintended pregnancy among unmarried adolescents in Nigeria in a multivariate framework. More specifically, it compares the socio-demographic characteristics of adolescents with unintended pregnancy and those of non-pregnant girls of similar age. Understanding and conceptualizing the similarities and dissimilarities of socio-demographic risk factors for unintended fertility among unmarried adolescents, and dividing them into taxonomically and analytically useful categories, will potentially add to our knowledge of the correlates of adolescent pregnancy in Nigeria and the rest of the developing nations. Finally, enhanced understanding of these could provide useful information for policymakers in the enactment of laws or development of programmes to benefit this population.

\section{Methods}

The study used 2008 Nigeria Demographic and Health Survey (NDHS) data. The sampling frame used for the 2008 NDHS was the 2006 National Population and Housing Census of the Federal Republic of Nigeria. The survey covered all the 36 states and the Federal Capital Territory, Abuja. The primary sampling unit (PSU), referred to as a cluster, was defined on the basis of Enumeration Areas (EAs) from the 2006 census frame. The sampling procedure used by 2008 NDHS was a stratified two-stage cluster design. In the first stage, 286 clusters were selected in the urban area, while

Table 1: Bivariate analyses of unintended pregnancy among unmarried adolescents and their socio-demographic characteristics $(N=6951)$

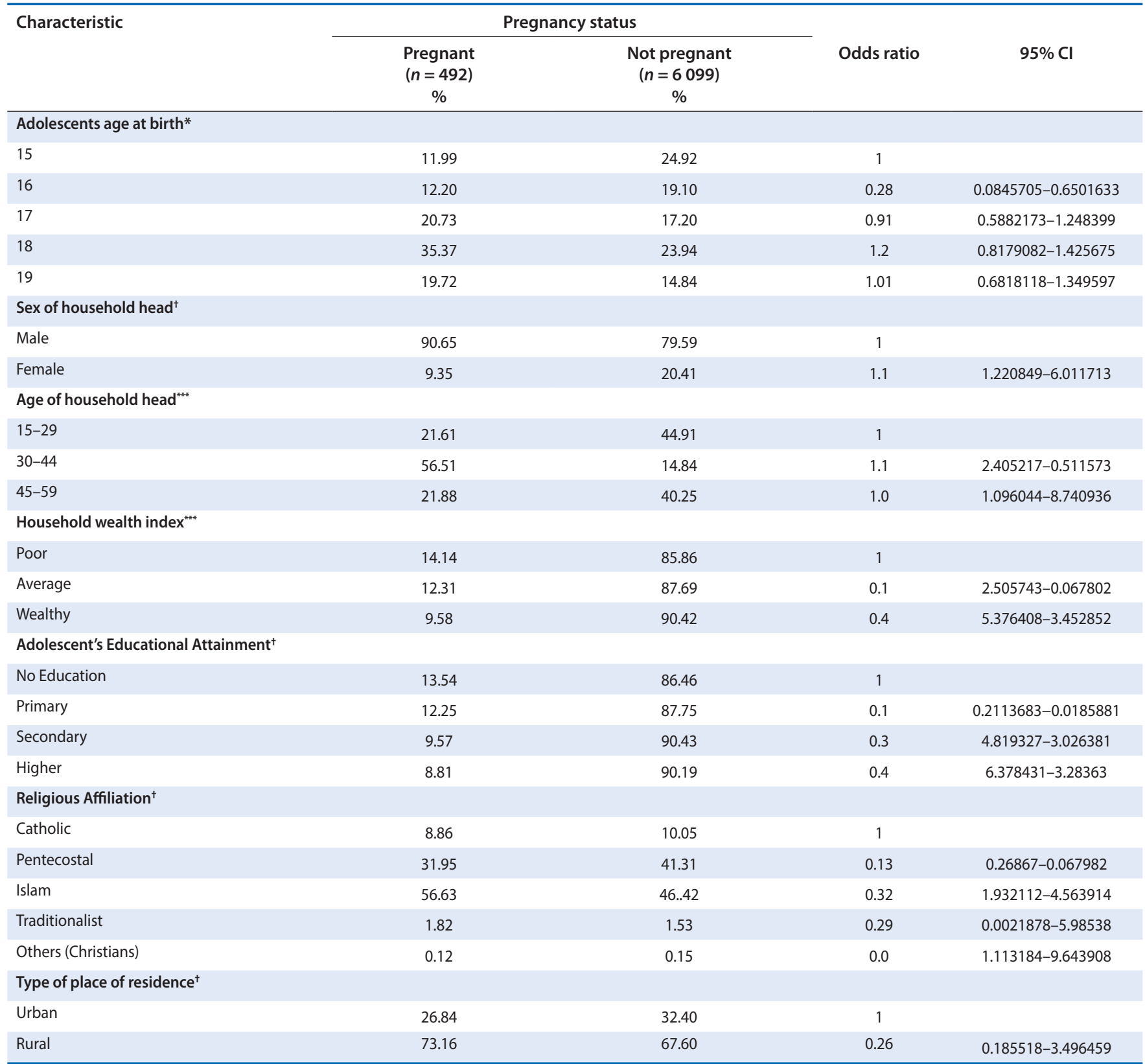

Source: calculated from the 2008 Nigeria demographic and health survey:

${ }^{*} p<0.05$.

***Statistically highly significant.

$+p<0.01$. 
602 clusters were selected in the rural areas. In the second stage of the selection, 41 households were selected in each cluster, by equal probability systematic sampling. Hence, a representative sample of 36410 households was selected for the 2008 NDHS survey, with 24684 households from the rural areas and 11726 households from urban areas.

Data used in the present study were collected from 6591 unmarried adolescents aged 15-19 years. Of these, 492 (7.46\%) adolescent girls were currently pregnant as at the time of the survey, while 6099 (92.54\%) were not pregnant. Married or unmarried adolescent girls with intended pregnancy were excluded in the study.

\section{Statistical analysis}

Univariate analyses and bivariate associations between socio-demographic and unintended pregnancy among unmarried adolescents were examined. Socio-demographic variables utilised include adolescent girls' maternal and paternal ages, and educational attainments, household wealth index, age and sex of household headship, family size, and household decision-maker. The associations of these variables were determined by computing odds ratio with $95 \%$ confidence intervals. Variables that were significant at this level were entered into a multivariate logistic regression model to estimate adjusted odds ratios of unintended pregnancy and the corresponding $95 \%$ confidence interval.

\section{Operational definitions \\ Unintended pregnancy}

Unintended or unplanned pregnancy refers to the sum of mistimed and unwanted pregnancies. A woman is assumed to have a mistimed pregnancy if she became pregnant at a time when she did not want to. On the other hand, a woman is assumed to have an unwanted pregnancy if the woman did not want to become pregnant at all, or in other words the pregnancy occurred when she wanted to have no more children. ${ }^{25}$

\section{Adolescent pregnancy}

Teenage pregnancy is defined as a teenage girl, usually within the ages of $13-19$, becoming pregnant. ${ }^{6}$

\section{Unmarried adolescent}

This is defined to mean a teenage girl within the ages of 13-19 who is not married. ${ }^{25}$

\section{Maternal age}

This is defined as the age of the mother in completed years at the time of delivery. ${ }^{26}$

\section{Paternal age}

Paternal age was defined as the age of the father in completed years at the time of delivery. ${ }^{26}$

\section{NDHS}

Nigeria Demographic and Health Survey. ${ }^{27}$

In the bivariate analysis of adolescent's fertility and socio-demographic variables at the individual and household levels, unmarried adolescents aged 18 experienced the highest rate of adolescent pregnancy. They were 1.1-times more likely to experience adolescent pregnancy compared to those aged 15 years. With regard to sex of household head, $90.65 \%$ of adolescent pregnancy occurred among male-headed households, while the odds ratio for adolescent pregnancy among female-headed households was $0.9(95 \% \mathrm{Cl}=-1.220-0.6011)$ with $9.35 \%$ of adolescent pregnancies. The highest proportion of adolescent pregnancy occurred in households whose heads were 30-44 years old, about $56.51 \%$. The odds of adolescent pregnancy among these groups was 14-times more likely compared to those between ages $15-29$ years.

Teenage pregnancy was statistically significantly associated with educational attainment or level. The more education an adolescent girl has, the less likelihood of such an adolescent girl to experience adolescent pregnancy. Adolescent girls from poor households reported the highest rate of adolescent pregnancy. Adolescent girls from wealthy households were $4 \%$ less likely to experience adolescent pregnancy compared to the reference category. Significantly more $(56.63 \%)$ of the teenage pregnant girls were Muslims ( $\mathrm{OR}=32, \mathrm{Cl}=0.193-0.456)$. Furthermore, the highest proportion of adolescent pregnancy occurred among unmarried adolescent girls in rural areas, about $73.16 \%$. The odds of adolescent pregnancy among unmarried adolescent girls in rural areas were 26-times more likely compared to their urban counterparts.

\section{Multivariate analysis \\ Results}

Age and sex of household head, adolescent's age and educational attainment, and type of place of residence were significantly associated with adolescent pregnancy $(p<0.05)$. Adolescent pregnancy was less likely to occur among female headed households compared to male children. $(\mathrm{OR}=0.56,95 \%$ $\mathrm{Cl}=0.3920-0.8073)$. Adolescents aged 18 were more likely to experience adolescent pregnancy compared to those of the reference group category $(\mathrm{OR}=2.4,95 \% \mathrm{Cl}=1.732-3.299)$. Educated adolescent girls were less likely to report adolescent pregnancy $(\mathrm{OR})=0.38$. Adolescent girls who are living in inner-city communities are 1.1-times more likely to report adolescent pregnancy $(95 \% \mathrm{Cl}=0.7316-1.356)$.

\section{Discussion}

This paper focused on socio-demographic risk factors for unintended pregnancy among unmarried adolescent Nigerian girls. During the 2003-2008 survey periods, there were 6591 adolescent girls aged 15-19. Of these numbers, 492 were currently with unintended pregnancy at the time of the survey, while 6099 were not pregnant. Our findings confirmed that, when using the bivariate analysis to examine the level of relationship between the dependent and independent variables, maternal and paternal ages were significantly associated with unintended pregnancy among unmarried adolescent Nigerian girls. In the multivariate analysis (Table 2), four factors remained statistically significant: age of household head $(\mathrm{OR}=3.06,95 \% \mathrm{Cl}=1.08-8.68)$; adolescents'age ( $\mathrm{OR}=8.51,95 \% \mathrm{Cl}=1.12-64.90)$; sex of household head $(O R=15.23,95 \% \mathrm{Cl}=1.43-162.45)$; adolescent girl's educational attainment $(\mathrm{OR}=10.67,95 \% \mathrm{Cl}=2.67-42.63)$; and type of place of residence.

If an adolescent girl was living in a household headed by a young adult (30-44), such an adolescent girl had a higher risk of experiencing adolescent pregnancy. There was a significant increase in the risk of adolescent pregnancy if the adolescent girls had no education or only primary education. For these adolescent girls, the OR was $82(95 \% \mathrm{Cl}=060-1.139)$. This finding is consistent with those of other studies in which associations between unwanted pregnancy and educational attainment and risk of childhood mortality were reported. ${ }^{25,26}$ Previous studies have shown that the risk of unintended fertility is higher among women with lower education (primary or less), women who reside in rural areas because of non-availability of proper medical attention, as well as women that never attended antenatal care..$^{25}$ In this study it was also observed that adolescent girl's education and age were important and significant predictors of adolescent 
Table 2: Adjusted odds ratios from logistic regression of unintended adolescent births and socio-demographic characteristics of adolescents with unintended pregnancy and those of non-pregnant girls $(n=492)$

\begin{tabular}{|c|c|c|}
\hline Characteristics & Odds ratio & $95 \% \mathrm{Cl}$ \\
\hline \multicolumn{3}{|c|}{ Age of household head* } \\
\hline $15-29$ & 1 & \\
\hline $30-44$ & 0.53 & $0.4209848-0.6776125$ \\
\hline $45-59$ & 0.21 & $0.1542932-0.3012827$ \\
\hline \multicolumn{3}{|l|}{ Adolescents age* } \\
\hline 15 & 1 & \\
\hline 16 & 1.2 & $0.8564493-1.888038$ \\
\hline 17 & 2.03 & $1.424112-2.9133$ \\
\hline 18 & 2.5 & $1.732442-3.299725$ \\
\hline 19 & 2.4 & $1.690283-3.470652$ \\
\hline \multicolumn{3}{|c|}{ Sex of household head* } \\
\hline Male & 1 & \\
\hline Female & 0.56 & $0.3920097-0.807327$ \\
\hline \multicolumn{3}{|c|}{ Adolescent's educational attainment } \\
\hline No education & 1 & \\
\hline Primary & 0.82 & $0.604124-1.13942$ \\
\hline Secondary/Higher & 0.38 & $0.2629758-0.5653821$ \\
\hline \multicolumn{3}{|c|}{ Type of place of residence } \\
\hline Urban & 1 & \\
\hline Rural & 1.1 & $0.7316658-1.356944$ \\
\hline
\end{tabular}

Source: Calculated from the 2008 Nigeria Demographic and Health Survey: ${ }^{*} p<0.01$.

pregnancy. In general, the results show that the risk of adolescent pregnancy in 2004-2008 reference periods was significantly higher among adolescent girls with no education followed by those with primary education, and the trend continued reducing as education increased among adolescent girls.

\section{Conclusions}

The current study shows that age of household, adolescents' age, sex of household head, adolescent girl's educational attainment, and type of place of residence were statistically associated with adolescent pregnancy. Households of non-pregnant adolescents had older adult heads, with higher educational attainment, and were wealthy.

\section{References}

1. Aigbe GO, Zannu AE. Differentials in infant and child mortality rates in Nigeria: evidence from the six geopolitical zones. Inter J Human Soc Sci 2012. 2000;2(16):206-14.

2. Stammers T. Sexual health in adolescents. Bri Med J. 2007;334:103-4. http://dx.doi.org/10.1136/bmj.39087.374653.BE

3. Thompson AA, Onyeonoru IP. A multivariate analysis of adolescent sexual behaviour in southwestern. IFE Psychol Int J. 2007;15:53-76.

4. Hamilton BE, Miniño AM, Martin JA, et al. Annual summary of vital statistics: 2005. Pediatrics. 2007;119:345-60.

5. Chalem E, Mitsuhiro SS, Ferri CP, et al. Gravidez Na Adolescência: Perfil Sócio-Demográfico E Comportamental De Uma População Da Periferia De São Paulo, Brasil teenage pregnancy: behavioral and socio-demographic profile of an urban. Cad. saúde pública. 2007;23:177-86.

6. UNICEF. Committing to child survival: a promise renewed (Progress Report 2012). New York: UNICEF; 2013.

7. Roehrig HR, Xanthakos SA, Sweeney J, et al. Pregnancy after gastric bypass surgery in adolescents. Obes Surg. 2007;17:873-7. http:// dx.doi.org/10.1007/s11695-007-9162-7

8. Doğan-Ateş A, Carrión-Basham CY. Teenage pregnancy among Latinas examining risk and protective factors. Hispanic J Behav Sci. 2007;29:554-69.
9. Amoran OE, Onadeko MO, Adeniyi JD. Parental influence on adolescent sexual initiation practices in Ibadan, NIGERIA. Int Quart Commun Health Educ. 2005;23:73-81. http://dx.doi.org/10.2190/U8VJ-0UFE-HRYU-J48L

10. Fatusi AO, Blum RW. Predictors of early sexual initiation among a nationally representative sample of Nigerian adolescents. BMC Public Health. 2008;8:136-50. http://dx.doi.org/10.1186/1471-2458-8-136

11. Aga S, Van Rossem R, Ankomah A. Community-level influences on early sexual initiation in Nigeria. Measure Evaluation Working Paper Series. 2006.

12. Ankomah A, Mamman-Daura F, Omoregie G, et al. Reasons for delaying or engaging in early sexual initiation among adolescents in Nigeria. Adoles Health Med Ther. 2011;2:75-84. http://dx.doi.org/10.2147/ AHMT

13. Odimegwu CO, Solanke LB, Adedokun A. Parental characteristics and adolescent sexual behaviour in bida local government area of Niger State, Nigeria. Afr J Reprod Health. 2002;6:95-106. http://dx.doi.org/ $10.2307 / 3583150$

14. Isiugo-Abanihe UC, Oyediran KA. Household socioeconomic status and sexual behaviour among Nigerian female youth. Afr Popul Stud. 2004;19(1).

15. Nichols D, Ladipo OA, Paxman JM, et al. Sexual behavior, contraceptive practice, and reproductive health among Nigerian adolescents. Stud Fam Plan. 1986;17(2):100-6. http://dx.doi.org/10.2307/1967070

16. Chimaraoke Ol. Masculinity scripts and abstinence-related beliefs of rural Nigerian male youth. J Sex Res. 2008;45:262-76.

17. Representations of sexual abstinence among rural Nigerian adolescent males. Sex Res Soc Policy. 2007;4:74-87.

18. Obi SN, Ozuma BC, Onyebuchi AK. Pregnancy in unmarried adolescents in Nigeria. Int J Gynecol Obst. 2002;77:157-9. http:// dx.doi.org/10.1016/S0020-7292(02)00025-5

19. Ezimokhai $M$, Ajabor $L N$, Jackson $M$, et al. Response of unmarried adolescents to contraceptive advice and service in Nigeria. Int J Gynecol Obst. 1981;19:481-5.

20. Olusanya OO, Arijesuyo AE, Olusanya OA. Parent-child communication and adolescent sexual behaviour among the Yoruba ethno-cultural group of Nigeria. Res Human Soc Sci. 2013;3:79-84.

21. Slap GB, Lot L, Huang B, et al. Sexual behaviour of adolescents in Nigeria: cross sectional survey of secondary school students. Bri Med J. 2003;326:15-20. http://dx.doi.org/10.1136/bmj.326.7379.15 
22. Hellerstedt WL, Fee RM, McNeely CA, et al. Pregnancy feelings among adolescents awaiting pregnancy test results. Public Health Reports. 2001;116:180-93. http://dx.doi.org/10.1093/phr/116.S1.180

23. Ihejiamaizu EC. Adolescent fertility behaviour in Nigeria: trends and determinants. Global J Soc Sci. 2002;1(1):67-74.

24. United Nations. Department of Economic, The Millennium Development Goals Report 2008. New York: United Nations Publications; 2008.

25. Izugbara Chibuogwu. Household characteristics and unintended pregnancy among ever-married women in Nigeria. Soc Med. 2013;8:4-10.
26. Whose child is dying? Household characteristics and under-five mortality in Nigeria. S Afr J Child Health. 2014;8:16-22.

27. National Population Commission (NPC) [Nigeria] and ICF Macro. Nigeria demographic and health survey 2008. Abuja, Nigeria: National Population Commission and ICF Macro; 2009 [cited 2013 Oct 13]. Available from: http://nigeria.unfpa.org/pdf/nigeriadhs2008.pdf

Received: 23-03-2014 Accepted: 22-08-2014 